\title{
Identify Social Enterprises
}

\author{
Jing Wang \\ School of Public Administration and Emergency Management, Jinan University, Guangzhou, China \\ Email: 1546113866@qq.com
}

How to cite this paper: Wang, J. (2018) Identify Social Enterprises. American Journal of Industrial and Business Management, 8, 1700-1715.

https://doi.org/10.4236/ajibm.2018.87114

Received: June 13, 2018

Accepted: July 14, 2018

Published: July 17, 2018

Copyright $\odot 2018$ by author and Scientific Research Publishing Inc. This work is licensed under the Creative Commons Attribution International License (CC BY 4.0).

http://creativecommons.org/licenses/by/4.0/

\begin{abstract}
Social enterprises have become an inevitable trend of future social development. At present, the development of Chinese social enterprises faces internal and external adversities, and the prospects of the development of social enterprises are not clear. In order to build a good environment for the development of domestic social enterprises, this article fully draws on international experience and combines with China's actual conditions, and evaluates the existing standards of certification for civil society enterprises in China from five dimensions: organizational goals, income sources, profit distribution, asset disposal, and profit distribution. On this basis, further proposals are proposed to improve public awareness of social enterprises and lay a practical foundation for future legislative work.
\end{abstract}

\section{Keywords}

Social Enterprise, Certification Standard, Analysis Dimension

\section{Introduction}

According to the international prevailing definition, a social enterprise refers to an organization that achieves social goals through enterprise operation. Since the 1990s, social enterprises have emerged rapidly around the world as an emerging business that breaks through government failures, market failures, and voluntary failures. The social purpose and financial sustainability characteristics, unique to social enterprises, make it an innovative model for solving many social problems. With the rapid development of society, the traditional way of collecting funds such as government purchases and social donations has not been enough to meet the drastic changes in social needs. Under this background, the theory and practice of social enterprises have risen quietly in China and attracted the attention of many academics and practitioners.

At present, there are two forms of social enterprises in China: civil non-enterprise 
and commercial registration companies, but their development is facing both external and internal dilemmas. The first is the external dilemma. The public's awareness of social enterprises is low, and their public welfare is in doubt. The public does not understand the economic behavior of civil non-corporate enterprises, and cannot pay attention to the social missions and social goals of industrial and commercial enterprises either. As a result, the credibility of social enterprises is insufficient. The second is the internal dilemma. The financial sustainability of social enterprises is low. Because of the traditional nature of social organization, civil non-businesses lack business experience in economic activities and have weak profitability. Business enterprises with the nature of social enterprises must also take into account the social mission and profitability goals, compared to other market economic entities, and their competitiveness is weak. These reasons have caused certain obstacles to the financial sustainability of social enterprises. Whether it is its low public awareness or weak financial sustainability, it is largely due to the lack of policies and legal support for social enterprises. The organizational form of social enterprises is inconsistent with the current legal system. The identity of social enterprises has been questioned by the public, and their orientation is limited to first-tier cities. This has led to problems in the regulatory legitimacy, moral legitimacy, and cognitive legitimacy, and further affected economic benefits and social benefits of social enterprises [1].

The current development of social enterprises in China lacks policies and legal support, and the government's attitude towards social enterprises is not clear [2]. Some scholars regard social enterprises as a combination of public policies, markets, and civil society, and believe that social enterprises will become an important force for future economic development, and may even be the true growth force of developed economies in the post-capitalist era, so social enterprise legislation is an inevitable trend. Combining with the legislative experience of China's social organizations, the legislative work of social enterprises is not so simple. It requires a long observation period. In the case that the legal form cannot correspond to the social enterprise, it is necessary for the civil society to formulate social enterprise standards and carry out certification [3]. Therefore, it has strong feasibility that social organizations with higher authority and authority formulate social enterprise certification standards and give social enterprises legal status to promote development.

China's civil social enterprise certification work has started. "Shunde District Social Enterprise Cultivation and Incubation Support Plan" and "China Charity Exhibition Social Enterprise Authentication Method" are both standards established by civil organizations for the identification of social enterprises. However, as an explorer, the domestic social enterprise certification standards still have certain flaws. Therefore, it is necessary to comment on the domestic certification standards and find out its shortcomings. Based on the experience of foreign countries, we propose suggestions for improvement in light of China's actual 
situation, promoting the standardized development of social enterprises from the bottom up, and enable the public to better identify social enterprises. At the same time, it also lays a foundation for future legislation. Considering this, this paper will build an analytical framework from the five dimensions: organizational goals, income sources, profit distribution, asset disposal, and governance structure based on past scholars' research to measure the existing certification standards for civil society enterprises in China, to provide reference for the formulation of relevant laws of the state social enterprise.

\section{The Exploration of China's Social Enterprise Certification Standards}

Since 2004, theories of foreign social enterprises have begun to be introduced to China in the form of forums and seminars. In particular, David Burnstein's "How to Change the World: the Power of Social Entrepreneurs and New Ideas", the publication of the Chinese version of Charles Reidbit's "The Rise of Social Entrepreneurs" in 2006 and the "Father of Microfinance" Mohammad Yunus' visit to China has made social enterprises a hot topic for the academic, practical, charitable, and media communities. This has further promoted the development of social enterprises in China. So far, Chinese social enterprises have experienced decades of development. Many scholars and practitioners have explored social enterprises, and Chinese social enterprises have also made remarkable achievements, such as the Shenzhen Youyou Group, Tianjin Hetong Nursing Home, Fujian Golden Sun Elderly Service centers, etc. They are successful social enterprise cases. However, the development of Chinese social enterprise theory and practice is still at an exploratory stage. The development of Chinese social enterprises also faces enormous challenges. There are both reasons for social enterprises themselves and reasons for external support for the environment. However, whether for internal or external reasons, social enterprises must first obtain legal status if they want to achieve long-term development. Currently, China lacks policies and regulations to identify social enterprise and even the government's official documents rarely mention the concept of "social enterprises". In recent years, some civil society organizations have drawn on the experience of Europe, the United States, and Hong Kong, and have formulated social enterprise certification standards in conjunction with actual conditions and actively carried out the identification of social enterprises. "The Social Enterprise Cultivation and Incubation Support Plan" of the Shunde Social Innovation Center and "the China Cixi Exhibition Social Enterprise Certification Method" at the Shenzhen China Charity Exhibition Center.

The Shunde District Social Enterprise Cultivation and Incubation Support Plan was launched in September 2014 by the Social Innovation Center of Shunde District and is the first domestic social enterprise standard for the purpose of social enterprise certification, “Accelerate by Evaluation". In 2015, it took the lead in launching the social enterprise certification in China. The review mainly in- 
cluded two links: field visits and comprehensive review. The social goals, social benefits, business models, economic benefits, management structure, democratic participation, and profit distribution of social enterprises were targeted for comprehensive considerations in many aspects. The first social enterprise certification identified a total of 3 social enterprises and 6 quasi-social enterprises. The scope of business is concentrated in the field of disability. In 2016, according to the practical situation and opinions of all parties, the Social Innovation Center released the "Supporting Plan for Social Enterprise Cultivation and Incubation in Shunde (Revised Edition)", and launched the second social enterprise certification work in the same year to conduct hierarchical certification for participating social enterprises. It is divided into A grade, AA grade, AAA grade.

In September 2015, China Charity Exchange Exhibition released the "China Charity Exchange Exhibition Social Enterprise Certification Procedure (Trial)" (hereinafter referred to as the "CCF certification"). This certification method was developed by the China Charity Exchange Exhibition Development Center in Shenzhen, the Peking University Civil Society Research Center, and the Chinese public welfare research. The unofficial certification jointly initiated and supported by the Institute, the Social Enterprise Research Center, and the Southern Capital Foundation has opened the first national social enterprise certification. The CCF defines the social enterprise as a business means and a social organization that aims to establish a purpose and a goal for the sustainable resolution of specific social issues. According to its definition of a social enterprise, an institution that applies for social enterprise certification needs to meet five basic conditions, including organizational goals, sources of income, profit distribution, staff structure, and registration information. After two certifications in 2015 and 2016, a total of 23 organizations have obtained social corporate identities, of which the second certification has adopted the method of hierarchical certification for the first time. According to the latest news, the 2017 CCF certification standards will be further improved, involving the adoption of different certification standards and procedures for social organizations and enterprise applicant organizations, lowering the threshold for certification, and prioritizing the social goals in the governance structure, solving social issues in a creative way, follow-up service support, etc.

The first social enterprise awards ceremony sponsored by China Social Enterprise and Social Investment Forum was held in Beijing on June 12, 2017. The Social Enterprise Award is aimed at "discovering outstanding representatives of Chinese social enterprises, looking for companies that focus on social pain points, and setting a benchmark for the social enterprise industry". The purpose is to recognize and encourage innovative solutions to major social issues facing China in a large-scale and systematic way. The selection criteria are divided into six major systems, including social mission, social influence, business model, innovation, core team resources, and sustainability. There are 19 secondary indicators. To some extent, this is also considered a social enterprise certification. 
Compared with the social enterprise certification standards of the Shunde Research and Development Center and China Charity Exchange Exhibition, the Social Enterprise Awards have higher standards, stricter requirements, and more comprehensive evaluations. The Social Enterprise Award is China's first internationally leading concept and the highest award for Chinese social enterprises. It does not apply to the certification of general social enterprises. However, some of its indicators can provide a strong reference for civil society organizations to improve the social enterprise certification standards.

\section{The Successful Experience of Foreign Social Enterprise Certification}

In recent years, with the rapid rise of social enterprises in the global context, the legislative work of various countries on social enterprises is gradually being carried out. In the process of continuously exploring legal theory, some countries have made remarkable achievements.

The United Kingdom, Italy, Finland, Latvia, Lithuania, Poland, South Korea, and the United States introduced laws to create new legal forms or to identify social enterprises [3]. Italy is the first country in the world to carry out social enterprise legislation. It is believed that institutions can be recognized as social enterprises if they meet the principle of "do not distributive profits", and at the same time they have participation from employees and beneficiary groups at the level of institutional governance. Its standards are too broad and have little significance for the substantive restrictions of social enterprises. This article, based on a comprehensive consideration of the development of foreign social enterprises, chooses representative civil society enterprise certification standards for discussion.

1) Yunus's Standard

Muhammad Yunus is a pioneer of social enterprises. The success of microfinance is by no means accidental. It is the outward appearance of insight into the nature of society and its profound knowledge. According to his own exploration of social enterprise theory and practice, Muhammad Yunus proposed a set of standards for social enterprise recognition.

- Enterprises must serve social goals rather than profit maximization;

- Financial sustainability;

- The investor does not pay dividends after recovering the initial investment;

- The investor's profit after recovering the initial investment is used to expand the scale of the company or improve product services;

- Environmental awareness;

- Employees receive market pay and enjoy a better working environment than market standards;

- Happy working.

The social enterprise identification standards formulated by Yunus relate to the triple bottom line, profit distribution, and employees. The triple bottom line 
is the indicator that social enterprises must meet, while other indicators do not have universal applicability. "Investment without dividends" has an inhibitory effect on social enterprises with double attributes. Why only abandon economic attribute in pursuit of social attributes? The purpose of an enterprise is to make profits, how can the economic attributes be displayed better if they do not distribute profits? Relying on commercial means to obtain income does not fully demonstrate its economic attributes. "A better working environment" and "happy work" are also difficult social standards. Social enterprises are generally small in scale, short in time, and immature in their mode of operation. At present, they cannot compete with commercial enterprises. In the case of weak economic capacity, even if it has the internal thrust of the social goal, it cannot reach this standard. Only when the scale of the social enterprise develops to a certain extent can the employee's working environment and treatment be further enhanced beyond that of the commercial enterprise. Of course, this is also the direction in which social entrepreneurs must work hard.

2) European EMES standards

The European Social Enterprise Research Network (EMES) is an institution that conducts social enterprise research earlier. On the basis of the European social enterprise development practice, it has developed a social enterprise certification standard. Many scholars have divided these indicators into four economic/entrepreneurial indicators and five social indicators (Roger Spear, 2005). This article divides specific indicators into economic, entrepreneurial, social, and governance indicators according to needs and related information on the EMES official website.

\section{Economicl entrepreneurial indicators.}

- Providing continuous behavior of products and services;

- There is a considerable degree of economic risk;

- Work that needs to be paid should be reduced as much as possible. Social indicators.

- Clear purpose of serving the community;

- Be initiated by a group of citizens or civil society groups;

- Limited profit distribution. Governance indicators.

- High degree of autonomy;

- Capital ownership has nothing to do with business decision-making authority;

- The nature of participation, participation of all parties affected by the organization in institutional governance.

According to the EMES European Research Network's definition of social enterprise recognition standards, the two focuses of social enterprises are the characteristics of multi-participation and the nature of multiple objectives. Specifically, its economic goals are mainly reflected in the requirement for institutionalized corporate operations, economic risks, and cost reduction; social goals are 
manifested in terms of institutional sponsors, service targets, and profit orientation; governance emphasizes institutional autonomy and democratic decision-making and participating subject. EMES starts with the goals of social enterprises and the characteristics of governance, and conducts a comprehensive assessment of social enterprises. At the same time, it needs to be pointed out that the above indicators do not constitute the standards of social enterprise norms, but that scholars provide an "ideal model" for social enterprise positioning. It is more like a tool to help researchers to better define the organizational category of social enterprises.

EMES is intended to give a benchmarking to measure and distinguish different types of social enterprises, rather than only if all the standards are met, can an institution be called a social enterprise [4].

3) SEM certification standards in the United Kingdom

The United Kingdom is a leader in social enterprises worldwide. In the United Kingdom, social enterprises do not have a legal form that fully corresponds to them. Social enterprises cannot be identified through registration types. However, the social enterprise industry has its own certification standards. At present, the authoritative is a social enterprise certification conducted by the British Social Enterprise Signing Company (SEM). There are six specific certification standards.

- Institutions can clearly reflect social and environmental goals;

- An independent organization;

- At least $50 \%$ of the revenue comes from market-based transactions;

- At least $50 \%$ of profits are applied to social and environmental goals;

- The remaining assets of the institution should be used for social and environmental purposes;

- Can provide evidence that the organization is achieving social/environmental goals.

The SEM certification standards recognize the goals of social enterprises, sources of income, profit distribution, and asset locking. For enterprises within one year of business activities, they only need to meet the criteria of one, two, four, but within 18 months of receiving the social enterprise logo certification, they must achieve the third standard, otherwise the certification license will be cancelled. In 2014, it also launched the Gold Social Enterprise Certification, focusing on governance, business ethics, and fiscal transparency. Although SEM certification is not an official behavior of the government, its certification standards are worthy of reference by Chinese social enterprises. In 2016, the "China-UK Social Enterprise Certification Standards Workshop" was held in Beijing to introduce and learn from the construction methods and practical experience of international social enterprise certification systems such as British social enterprise logos, so as to localize social enterprise certification standards and promote the ecological environment construction of Chinese social enterprises.

4) US B-corp certification 
The United States Co-Benefit Lab (B-Lab) is initiating a global commercial campaign. Establishing a certification system for B Corp (Chinese scholars call it a "B-type enterprise") by using a set of very charitable standards to certify a batch of commercial enterprises. It integrates business with public welfare and creates economic, social and environmental values. Its certification content mainly includes environmental responsibility, employee treatment, customer satisfaction, community influence and transparency.

At present, more than 2000 companies in 130 industries in more than 50 countries have obtained B-Corp certification. China's "first response" is to obtain B-Corp certified companies. Jay Coen Gilbert, co-founder of B-Lab, once said that entrepreneurs and investors need a set of standards to separate companies that practice higher levels of social responsibility from companies that shout marketing slogans. From this we can see that B-Corp authentication essentially uses commercial companies as the authentication object and does not include non-profit organizations. However, its emphasis on social environmental performance, employee benefits and work environment can also provide reference for the certification of commercial enterprises in Chinese social enterprise certification.

The above four types of standards are more influential civil society enterprise certification standards in the world. Each type of standard includes the understanding of the connotation and extension of social enterprises by various agencies and the uniqueness of local social enterprise practice. Due to the differences in the historical traditions and social realities of different regions and countries, there are some differences in the standards for their identification. It should be particularly pointed out that the B-Corp certification in the United States does not make special provisions on income sources and profit distribution. This may be due to the fact that its target is mainly commercial enterprises, and it also reflects the different positioning of social enterprises in different countries and regions. The United States is biased toward a "market economy", while Britain and the EU are more inclined to a "social economy". However, in general, most certification standards include dimensions such as social goals, financial sustainability, profit distribution, and governance structure. Wang Shiqiang also believes that national social enterprise identification standards include the five dimensions of social mission, income sources, profit distribution, asset disposal, and governance structure. China's social enterprises can also be identified accordingly [3]. The formulation of social enterprise certification standards is the most recent international development trend [4]. Both domestic and foreign countries are actively practicing and exploring. The experience of foreign social enterprise certification provides precious reference resources for China's social enterprise certification.

\section{Insufficiency of Chinese Social Enterprise Certification Standards}

The purpose of this paper is to form a more comprehensive and widely accepted 
social enterprise certification standard. To form such a set of standards, we must comprehensively consider various influencing factors to better grasp the connotation and attributes of social enterprises. As far as China's current civil society enterprise certification standards are concerned, there are still some deficiencies. Based on the research of many scholars, this article will also analyze existing certification standards from five dimensions: organizational goals, income sources, profit distribution, asset disposal, and governance structure.

The first is the organizational goal. Social enterprises are organizations with dual attributes that achieve social goals through enterprise operations. In terms of its connotation, it should roughly have four characteristics: first, it should be active in the social field; second, it should be devoted to social innovation; third, it should be aimed at realizing social benefits; and fourth, it must be regulated by relevant specific laws [5]. Therefore, the goal of social enterprises is to solve social problems with innovative means to achieve social benefits. The certification standards of the Shunde Social Innovation Center require that companies have a clear social mission and social goals and can create additional social values. The specific measure is through the company's articles of incorporation or long-term investment of more than $50 \%$ of the company's net profit to support social organizations or solve specific social problems. The regulations stipulate that it will not necessarily be implemented, especially for A-class companies. This standard is more difficult to verify and is equivalent to "virtual"; for 50\% of net profits, it provides annual financial reports on AA and AAA social enterprise certification requirements. However, for Class A companies, they do not require proof of relevant materials and their social benefits cannot be measured. The starting point of the Shunde Social Innovation Center is to promote the development of social enterprises and foster a good social enterprise environment. However, the social goal is the primary goal of social enterprises and the bottom line that social enterprises must adhere to. It must be rigorously treated.

The second is the source of income. Gaining income through business operations is the fundamental difference between social enterprises and traditional charitable organizations. Social enterprise identification standards in Western countries all require corporate income sources. The China Charity Exchange Exhibition is certified by legally registered companies or social organizations and requires that $50 \%$ of revenues come from sales of goods, trade, or project income. The Shunde Social Innovation Center is a commercial enterprise. It only requires a stable source of income, and it does not specify the type of income and the proportion of income. Social enterprise is an organization with dual attributes. Its economic nature is also the basis for the survival of social organizations. Therefore, the source of income is still quantified as far as possible. It is also worth noting that the social enterprise certification standards at home and abroad do not stipulate the income and expenditure situation of social enterprises, that is, whether they can participate in social enterprise identification only when the enterprise receives more than support and is in a profitable state. 
This is an independent survival of social enterprises. The consideration of competence relates to the future development of social enterprises.

The third is the distribution of profits. Social enterprise is not to obtain economic income, and income is only a means to achieve its social goals, to avoid pursuing the maximization of individual or shareholder interests, but to use profits for the realization of social goals or the development of social enterprises. At the same time, we must understand that only profitable social enterprises can continuously achieve their social goals. Social enterprises are not the same as traditional non-profit organizations. Their development scale and development speed need to rely on civil capital investment. China's current civil capital flows to financial markets, real estate, and other industries. Social enterprises must compete with these highly profitable industries for limited capital. Taking this level into consideration, a certain percentage of profit distribution can be appropriately carried out to guide civil capital flows to social enterprises, and it can also play an effective incentive role for internal management. The Shunde Social Innovation Center accreditation standards allow social enterprises to distribute profits. For different levels of social enterprise certification, the proportion of profit distribution is different. Category A does not require AA category does not exceed 50\%, AAA category does not exceed one third. The Chinese CITI exhibition certification standards have different requirements according to the nature of the certification body. Social enterprises of commercial nature can allocate no more than $50 \%$ of profits, while social enterprises of social organizations do not allow distribution of profits. This is in contrast to non-profit organizations in China. The spirit of relevant laws and regulations is the same. According to the degree and nature of the development of social enterprises, different profit distributions are stipulated, which can better promote the development of social enterprises.

The fourth is asset disposal. The requirement of "asset locking" is essentially to ensure the social "motivation" of social enterprises. Countries generally provide for the use of surplus assets for social or environmental purposes after the cancellation of social enterprises. Institutional founders cannot privatize assets. However, some countries allow a certain percentage of assets to be allocated or freely disposed of. The Shunde Social Innovation Center accreditation standards allow the AA social enterprises to allocate no more than $50 \%$ of their assets. AAA social enterprises require all the remaining assets to be donated to social enterprises, public welfare funds or other public welfare social organizations. The China Charity Exchange Exhibition did not regulate the disposal of assets. Because its certification target is a commercial enterprise or social organization, and according to the "Provisional Regulations for the Registration of Civil Non-enterprise Units", the authority to dispose of surplus assets after the cancellation of the social organization is delivered to the competent business unit, which is usually authorized by a government agency or government. Considering that the development of China's public welfare undertakings is in its infancy, 
it is necessary to actively guide the development of social enterprises in the direction of public welfare, and we must adhere to the public welfare nature, and the surplus assets should not be distributed.

The fifth is governance structure. Broadly speaking, governance structure refers to a series of organizational settings that ensure the achievement of institutional goals. The participation of stakeholders can optimize the governance structure, and the council is an effective way for stakeholders to participate in governance, as Mason said: Diverse stakeholder engagement at the board level is very helpful because it encourages organizations to mobilize resources in the process of pursuing strategic development. Social enterprises in many developed countries have typical characteristics of a high degree of autonomy, multi-participation, and democratization. European scholars have emphasized that social enterprises are composed of stakeholders. They believe that social enterprises attach importance to democratic participation in management, and that decision-making follows the "one person, one vote" principle [3]. This can not only better achieve the goals of social enterprises, but also make social enterprises more effective. More importantly, it can get rid of government or third sector control to achieve autonomy. In contrast, in many developing countries, social organizations have high levels of government compliance, and social enterprises have low autonomy and participation. China's current civil society enterprise certification standards do not require social enterprise's multi-participation and democratic decision-making. From the analysis of China's existing institutional mechanisms, the government is still in a leading position and has interfered too much with the market and civil society. Social enterprises are at the intersection of markets, public policies, and civil society, so it is difficult to get rid of the constraints of institutional mechanisms and the shackles of historical traditions. However, in order to achieve a better social mission, democratic decision-making and the participation of multiple stakeholders in social enterprise operations are indispensable.

\section{Improve China's Civil Society Enterprise Certification Standards}

In the process of development, social enterprises gradually formed a unique difference from commercial enterprises and traditional charitable organizations, its operation mode. Due to the influence of historical traditions and social reality, China's social enterprises have also shown different characteristics from social enterprises in other countries. Given the unclear development prospects of Chinese social enterprises, how the social enterprise certification standards are formulated will greatly affect the enthusiasm of social enterprise certification and the sustainability of development. Therefore, on the basis of a reasonable reference to the experience of foreign social enterprise certification, fully respecting China's actual national conditions, grasping the degree of goodness, and formulating a practical and feasible social enterprise certification standard, is the ulti- 
mate goal of this article. In order to broaden the social enterprise network and better guide the development of social enterprises, it is also a direction that the social enterprise certification system needs to work hard to carry out social enterprise classification certification and classification certification. Currently, graded certification has been practiced in many places. For example, the Social Innovation Center of Shunde classifies social enterprise certification into three categories: A, AA, and AAA. Hong Kong's social enterprise certification is divided into Chuangqi, Chuangzhi and Chuangjin. At the four levels of Chong Kou Yue, the aforementioned British SEM certification also has Gold Social Enterprise Certification. The higher the certification level is, the greater the width and depth of the certification standard requirements is. This article divides social enterprise certification into three levels, elementary, intermediate and advanced. Combining the above analysis of domestic social enterprise recognition standards, we still proceed from the five dimensions of organizational goals, income sources, profit distribution, asset disposal, and governance structure to further improve civil society enterprise certification standards in an effort to promote an open and inclusive society, the formation of corporate ecosystem.

1) Organizational goals

According to Wang Ming, Zhu Xiaohong [5], defining the connotation of social enterprises, social enterprises refer to enterprises that are active in certain social fields, committed to innovation, and achieve social benefits. Service areas, social innovation, and social benefits are important indicators for measuring social enterprises. This article will also measure the organizational goals of social enterprises from these three aspects. Of course, the core is the realization of social benefits.

The first is service area. At present, social issues are complex and diverse, and involve a wide range of fields. Social enterprises must understand. It defines the service areas of the organization and the specific social issues to be solved, and it is set out in the organization charter. Social goals can be poverty alleviation, disability, employment promotion, education, medical care, environmental protection, etc. There is no excessive restriction on the scope of services provided by social enterprises, as long as they are carried out to promote social development and progress. Social enterprises must not produce negative external effects of the ecological environment in the process of achieving social goals. At the same time, they must also pay attention to employee benefits and create a good working environment for employees.

The secondly is social innovation. Some scholars believe that the biggest feature of social enterprises is innovation. The body is the product of social entrepreneurs who solve social problems with innovative spirit. In the course of business development, social enterprises must embody their own spirit of innovation, which can be the innovation of ideas, or the innovation of methods, modes, or means. Because social enterprises must simultaneously take into account economic and social goals, they must continue to innovate in order to have more 
advantages in the market competition than ordinary commercial enterprises in order to gain a foothold in the market. The criterion for measuring its innovation is to provide a social enterprise development plan and determine whether it is innovative through the review of social enterprise development plans.

The third is social benefits. The realization of social benefits is the ultimate goal of social enterprises and also their social mission. The organization applying for certification must submit an annual summary, and the assessment report on the influence of social enterprises provided by third parties should also be used as evidence for measuring the social benefits of social enterprises.

2) Sources of income

The way in which social enterprises earn income is not unique. Obtaining operating income is an important feature of social enterprises that is different from traditional charities. However, social enterprises are dual-purpose organizations that are both economic and social. Social enterprises can also obtain non-operating revenues such as venture capital ventures. The way and proportion of income sources of social enterprises are important manifestations of their attributes.

The first is the proportion of social enterprise income. Generally speaking, it is internationally demanded that the income of social enterprises exceed $50 \%$ from the sales of products or the provision of services. Considering that the target of social enterprise certification in this article is the civil and non-profit, and one of the important sources of income for civil and non-governmental is the government purchase, we need to include government purchase income in our certification standards, that is, $50 \%$ or more of the income of social enterprises in the business process, from providing products, services, or government purchases.

The second is the sources of income are diversified. Gaining income through market transactions is only part of their income. To achieve financial sustainability, you must have a diversified source of income, such as social venture capital, venture philanthropists, and social donations. Diversified sources of income can reflect the ability of social enterprises to acquire capital, not only financial capital, but also social capital. For some venture capitalists, they are not short of funds. What they lack is only institutions and projects worth investing in. If you can get the favor of venture capitalists, it is not only trust, but also the establishment of a social network, which is crucial to the sustainable development of the organization. Primary social enterprises have a short development time, weak strength, and difficulty in obtaining social enterprise capital, so they are not required.

3) Profit Distribution

All along, "whether or not to distribute dividends" has been a hot topic that has caused controversy. However, as we analyzed above, the development of social enterprises requires a certain degree of profit distribution to guide civil capital inflows, as long as they grasp the distribution ratio. One of the major inter- 
national trends is to allow a certain proportion of profit distribution. For example, Muhammad Yunus, who initially opposes the dividends of social enterprises, also allows for the proper distribution of profits as he explores social enterprise development practices; the UK community interested company initially limited the "maximum dividend limit per share" and gradually relaxed it later, and will completely abolish the "maximum dividend limit per share" by 2014. Of course, the above-mentioned viewpoint of profit distribution, combined with the actual situation in China, applies only to domestic social enterprise certification with commercial nature.

First, social organizations of a social organization cannot distribute profits. The people-run non-enterprise unit is a form of legal organization subject to the "Provisional Regulations on the Management of Civil Non-corporate Units". It is stipulated in the regulations that civil non-corporate units cannot distribute profits, even if they are recognized as social enterprises by civil society enterprise certification agencies. It will not change its legal form. It still needs to follow the laws and regulations.

Second, social enterprises of a commercial nature can distribute profits. This involves the issue of whether companies with no profit can apply for certification and the proportion of profit distribution. For the former question, whether profitability is an important consideration for the viability of social enterprises. A company must have the ability to survive independently, that is, profitability, in order to be certified as a social enterprise. This is the most basic requirement. So here is a two-year period as a measure of the standard, that is, companies must continue to profit for two years before they can apply for certification as a social enterprise. As for the proportion of profit distribution, different levels of social enterprises can enjoy different proportions of profit distribution. Based on the standards of some countries in Hong Kong and Europe, this paper believes that primary social enterprises can distribute no more than $50 \%$ of profits, medium-sized social enterprises do not exceed $35 \%$ of profits, and senior social enterprises do not exceed 20\%. Different levels of social enterprises have great differences in their own development ability, access to resources, and social capital stock. The lower the level of social enterprise is, the more need the financial support, and correspondingly it can be allowed to allocate a higher proportion of profits. At the same time, social enterprises must provide annual financial reports for the past two years in order to measure their financial status; allow the certification body to put financial reports on the official website for monitoring by all parties to reflect its financial transparency.

4) Asset Disposal

Unlike ordinary enterprises, donors and investors of social enterprises do not become "owners" of social enterprises (i.e., resource providers do not enjoy property ownership) after the occurrence of donation activities and investment activities, nor can they perform the remaining assets of the enterprise; request and control. The remaining property after termination cannot be recovered by 
the funder and can only be transferred to other public sectors (government or other non-profit organization). This article also advocates the principle of "asset locking", that is, surplus assets are not allocated to better ensure the social motivation of social enterprises.

5) Governance structure

Applying a metaphor in the business world, "Corporate governance structure is the nervous system of an enterprise". It can be seen that the governance structure is important to a business. It is not only the structural arrangement of the organization, but also an indispensable factor in the development of the organization's operations. For social enterprises, their governance structure needs to reflect at least three points: the participation of multiple stakeholders, democratic decision-making, and independent autonomy.

First, the participation of multiple stakeholders. The composition of the board of directors of social enterprises must reflect multiple stakeholders. This is an effective way to realize the public interests of the society and prevent certain minority interest groups from mastering the business decision-making power. Stakeholders vary according to the area of activity of social enterprises, but employees and beneficiary groups must be taken into account.

Second, democratic decision-making. The EMES standard proposes a democratic decision-making method where "capital ownership has nothing to do with business decision-making power". Democratic decision-making is that the members of the organization share the decision-making power, that is, the "one person, one vote" principle. The capital owner and other stakeholders make decisions together so that the decision-making process respects the opinions of each decision-maker.

Third, independent autonomy. Social enterprises must be independent of government agencies or charitable foundations to achieve institutional autonomy. By means of self-government, the healthy operation of the organization is realized.

\section{Conclusion}

The purpose of this paper is to form a more comprehensive and widely accepted social enterprise certification standard. On the basis of exploring the international social enterprise certification standards, and the analysis of the insufficiency of China's social enterprise certification standards, we further put forward suggestions for improvement and measures. Through this article we know that the development of social enterprises in China is not yet mature compared with Western countries. In order to further promote the development of social enterprises in China, we need to improve organizational goals, income sources, profit distribution, asset disposal, and governance structures. Social innovation and social benefits are important indicators for measuring social enterprises.

\section{References}

[1] Sun, Y.F. and Li, S. (2012) On the Legitimacy of Social Enterprises. Journal of Social 
Work, 8, 37-39.

[2] Jin, R.X (2016) Status Quo, Analysis and Development Strategy of Chinese Social Enterprises. Lanzhou Journal, 10, 188-195.

[3] Wang, S.Q. (2012) The Concept of "Social Enterprise” Analysis. Journal of Wuhan University of Science and Technology (Social Science Edition), 5, 495-500.

[4] Wang, S.Q. Social Innovation Paper.

[5] Wang, M. and Zhu, X.H. (2010) Outline of Social Enterprise. China Nonprofit Review, 2, 1-31. 